\title{
PEGylated versus non-PEGylated magnetic nanoparticles as camptothecin delivery system
}

\author{
Paula M. Castillo ${ }^{1,2}$, Mario de la Mata ${ }^{3}$, Maria F. Casula ${ }^{1}$, José A. Sánchez-Alcázar ${ }^{3}$ \\ and Ana P. Zaderenko*2
}

\section{Letter}

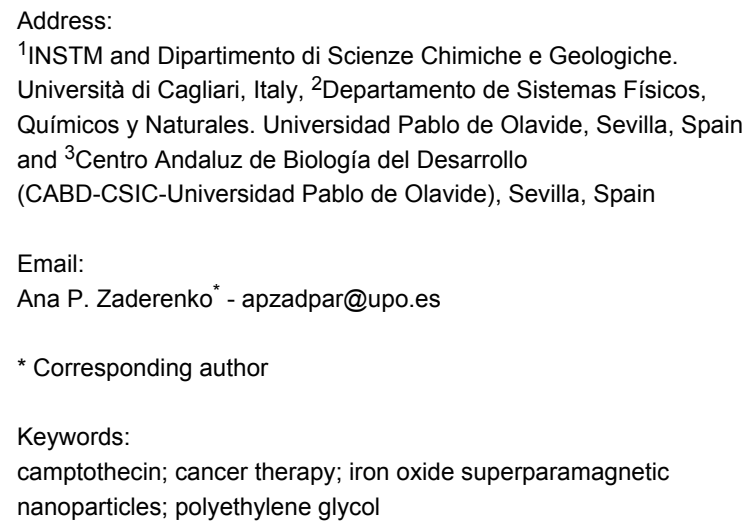

\begin{abstract}
Camptothecin (CPT; $(S)$-(+)-4-ethyl-4-hydroxy-1H-pyrano[3',4':6,7]indolizino[1,2-b]quinoline-3,14-(4H,12H)-dione) is a highly cytotoxic natural alkaloid that has not yet found use as chemotherapeutic agent due to its poor water-solubility and chemical instability and, as a consequence, no effective administration means have been designed. In this work, camptothecin has been successfully loaded into iron oxide superparamagnetic nanoparticles with an average size of $14 \mathrm{~nm}$. It was found that surface modification of the nanoparticles by polyethylene glycol enables loading a large amount of camptothecin. While the unloaded nanoparticles do not induce apoptosis in the H460 lung cancer cell line, the camptothecin-loaded nanoparticle formulations exhibit remarkable proapoptotic activity. These results indicate that camptothecin retains its biological activity after loading onto the magnetic nanoparticles. The proposed materials represent novel materials based on naturally occurring bioactive molecules loaded onto nanoparticles to be used as chemotherapeutic formulations. The procedure seems apt to be extended to other active molecules extracted from natural products. In addition, these materials offer the potential of being further implemented for combined imaging and therapeutics, as magnetic nanoparticles are known to be multifunctional tools for biomedicine.
\end{abstract}

\section{Introduction}

Camptothecin (CPT) is a quinoline based alkaloid, which exhibits a potent cytotoxic activity against a broad spectrum of tumours [1-3]. While most antineoplastic agents inhibit cancer cell proliferation by binding to DNA, CPT antitumor activity is due to inhibition of the nuclear enzyme topoisomerase I $[4,5]$. In spite of its potential as chemotherapeutic agent, CPT suffers from a reduced in vivo antitumor efficacy owing to its poor water-solubility and chemical instability (Figure 1). CPT- 
derivatives with improved solubility and stability have been developed; nevertheless their overall therapeutic impact is modest due to their lower activity when compared to CPT [6,7].
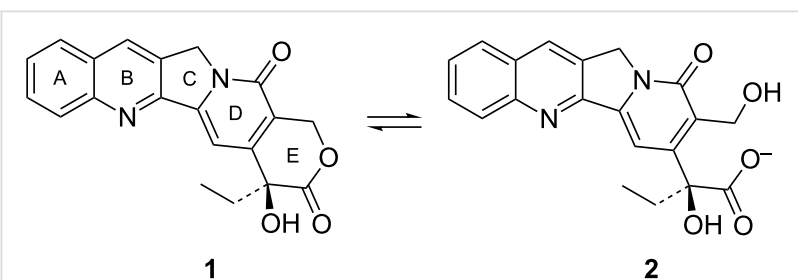

Figure 1: Molecular structure of (S)-(+)-camptothecin (1) and its inactive form (2) through lactone ring hydrolysis at physiological $\mathrm{pH}$.

An additional drawback related to the use of chemotherapeutic drugs refers to their lack of selectivity and, consequently, to their undesirable side effects. Due to the combined impact of cancer together with adverse side effects of many conventional chemotherapeutic agents, a significant effort is devoted to the design of nanoparticle vectors for cancer therapy [8-10]. Concerning CPT, attempts to improve its solubility and stability by means of nano-formulations cover a wide range of organic nanomaterials [11-19]. Noticeably, a cyclodextrin-containing polymer-CPT nano-formulation is currently undergoing phase II clinical trials [20].

Superparamagnetic iron oxide nanoparticles (SPION) are particularly promising as delivery systems due to their low toxicity and their ability to be used both in cancer diagnosis and therapy [21-23]. SPION can be effectively used as contrast agents for magnetic resonance imaging [24,25], as carriers for chemotherapeutic drugs [26-28] and to destroy cancer cells by acting as heat mediators in hyperthermia treatments [29-31]. Despite their interest, few attempts to develop CPT-delivery systems based on SPION have been reported [32-34], and none of them examine their ability to adsorb CPT, nor takes advantage of the desirable properties offered by polyethylene glycol (PEG) as coating polymer in nano-formulations. PEG has been widely used in the formulation of nanoparticles for biomedical applications, both because of its biocompatibility and its effectiveness in camouflaging nanoparticles from opsonins [35]. Recently, it has been described that PEG coating further reduces SPION cytotoxicity [36]. Moreover, PEGylated CPT has demonstrated its capability to lock the CPT E ring in its desired active lactone configuration [37].

Herein, we report a simple method to synthesise PEG-coated ultrasmall magnetite (USM) nanoparticles, and we examine the ability of both, bare and PEGylated USM nanoparticles, to conjugate CPT.

\section{Findings}

USM nanoparticles were synthesised through an iron co-precipitation method under alkaline conditions as described by Bee et al. [38] with slight modifications [39] (for detailed descriptions of the experimental procedures see Supporting Information File 1). As shown in Figure 2a, the USM nanoparticles are nearly spherical, with an average particle diameter of $14.0 \mathrm{~nm}$ and a standard deviation of $2.0 \mathrm{~nm}$, and monocrystalline (Figure 2b). The electron diffraction pattern corresponds to the spinel iron oxide nanocrystalline phase (Figure 2c).

Further insights into the crystalline structure were obtained from X-ray diffraction (XRD) patterns. Figure 3 reports the XRD pattern of our USM nanoparticles compared to a reference of a commercial magnetite standard. Although it is not possible to unambiguously ascribe the obtained pattern for USM nanoparticles to magnetite rather than to the isostructural spinel ferric iron oxide (maghemite), the XRD sample of the USM nanoparticles is consistent with the formation of magnetite. The peak broadening of the XRD pattern of the USM sample is in agreement with its nanocrystalline form. In

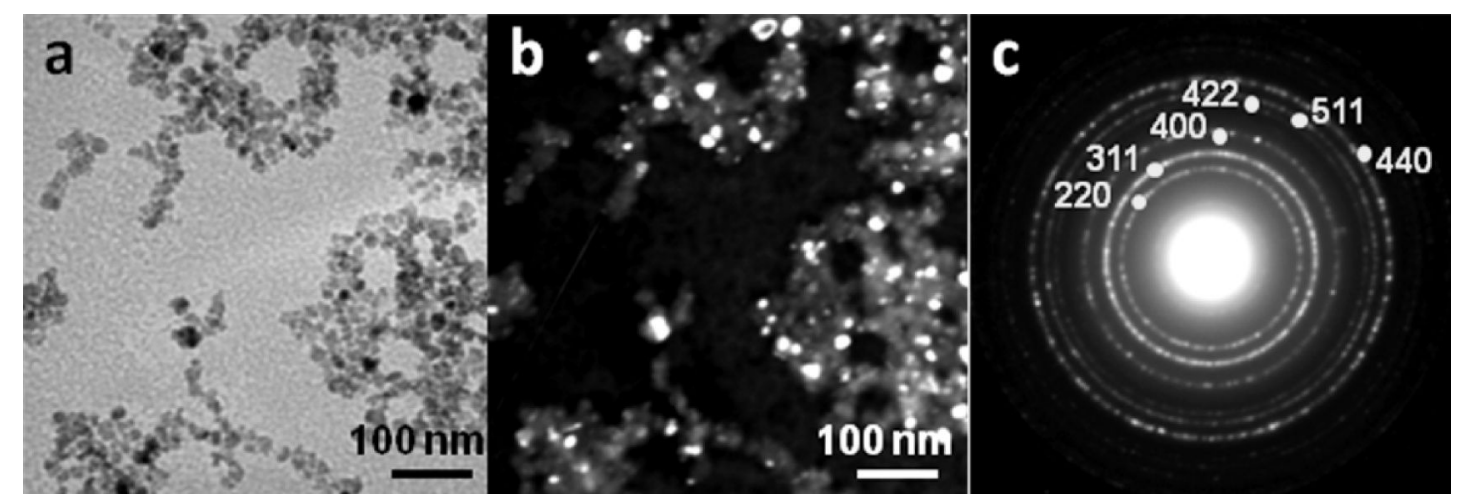

Figure 2: Bright field (a) and dark field (b) transmission electron microscopy (TEM) images and diffraction pattern (c) of USM nanoparticles. 
particular, the average size determined by line profile analysis is $11.0 \pm 1.0 \mathrm{~nm}$, in good agreement with the TEM data.

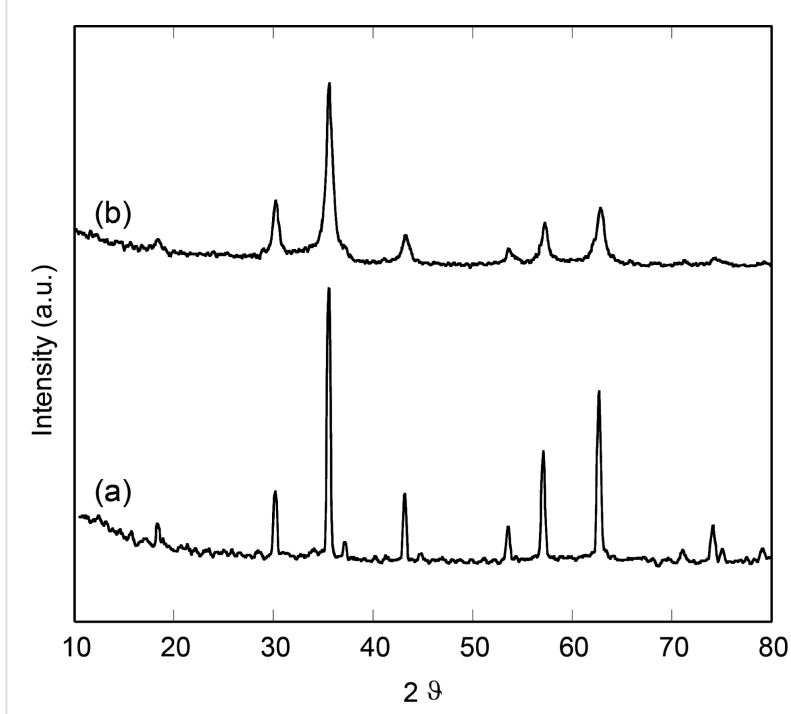

Figure 3: XRD spectrum of standard magnetite (a) and USM nanoparticles (b).

The USM sample readily responds to an external magnet and the main magnetic parameters, as derived by SQUID magnetometry characterisation, are summarised in Table 1. ZFC-FC magnetisation curves indicate that the USM nanoparticles exhibit a superparamagnetic behaviour and that most of the particles are blocked at room temperature, the blocking and maximum temperatures being out of the investigated range. The saturation magnetisation $\left(M_{\text {sat }}\right)$ as obtained from the hysteresis curve collected at $5 \mathrm{~K}$ was measured to be around $72 \mathrm{emu} \cdot \mathrm{g}^{-1}$ which is close to the value of bulk magnetite and maghemite (ca. 90 and $80 \mathrm{emu} \cdot \mathrm{g}^{-1}$, respectively). A decrease in saturation magnetisation values is often observed in nanoparticles and ascribed both to the effect of surface atoms and to a reduced crystallinity compared to their bulk counterparts [40]. As shown by the very low residual magnetisation value as compared to the saturation magnetisation, the sample at $5 \mathrm{~K}$ is nearly saturated at high fields and is mainly in the blocked state.

Table 1: Main magnetic parameters as derived for the USM sample by SQUID magnetometry: Maximum and separation temperatures ( $T_{\max }$ and $T_{\text {sep }}$ ) as obtained by ZFC-FC magnetization curves; coercive field $\left(H_{\mathrm{c}}\right)$, saturation magnetization $\left(M_{\mathrm{sat}}\right)$; residual magnetization $\left(M_{\mathrm{r}}\right)$ and residual versus saturation magnetization values $\left(M_{\mathrm{r}} / M_{\text {sat }}\right)$ as obtained by the hysteresis curve collected at $5 \mathrm{~K}$.

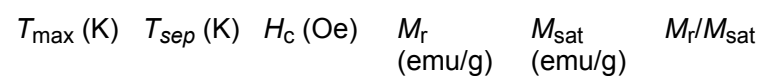

$\begin{array}{llllll}>325 & >325 & 139.218 & 6.238 & 72.402 & 0.086\end{array}$

The obtained USM nanoparticles were PEGylated according to the strategy depicted in Scheme 1. In a typical PEGylation procedure the surface of USM nanoparticles was first coated with succinic acid, in order to allow for the subsequent covalent linkage of bis(3-aminopropyl)-terminated poly(ethylene glycol) through carbodiimide chemistry.

It is known that the use of succinic acid as stabilizing agent during the synthesis of magnetite nanoparticles decorates their surface with acid molecules. Nevertheless, the amount of succinic acid that has been attached to the surface is low, as can be judged from the IR data available [41]. Given that the amount of succinic linkers on the nanoparticle surface limits the uptake of PEG, it is crucial to ensure higher amounts of

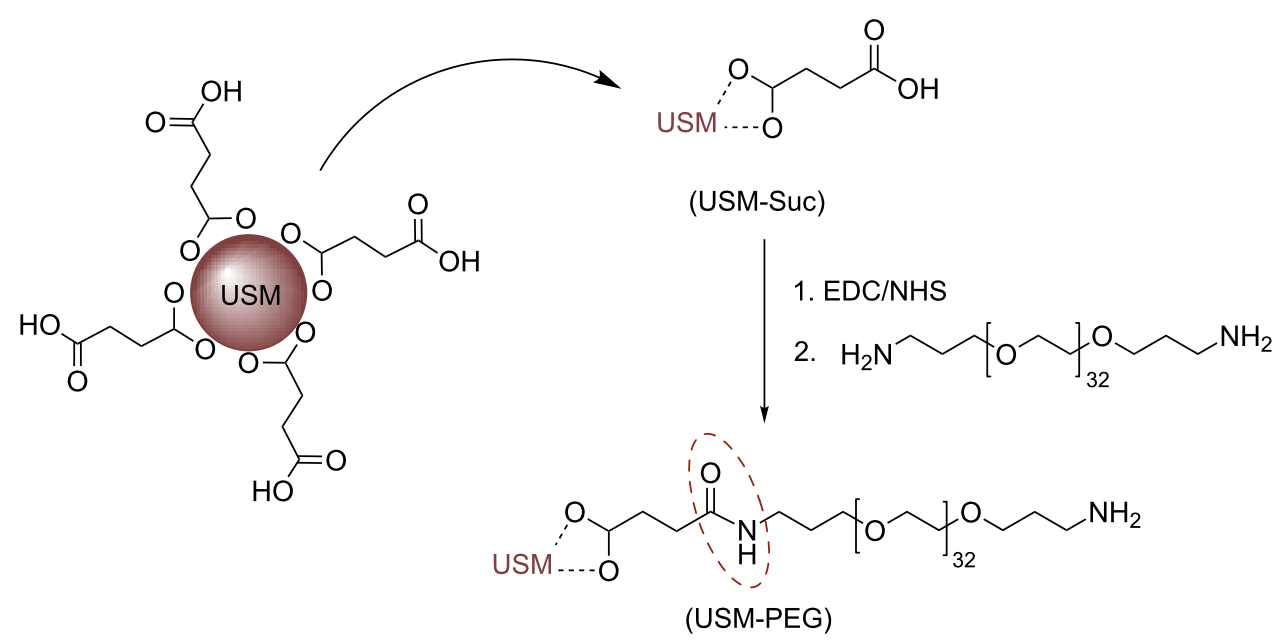


carboxylic groups on the nanoparticle surface. In order to increase the acid coating, we have investigated a different approach which relies on the direct incubation of previously synthesized magnetite nanoparticles with the acid in aqueous medium, instead of including it into the co-precipitation reaction medium. By this approach we were able to obtain USMSuc nanoparticles whose surface is densely covered with carboxylic acid.

Figure 4 shows the FTIR spectra of USM-Suc and succinic acid in the most commonly used mode: transmittance. However, in order to make a quantitative comparison between peak areas, the corresponding absorbance spectra were used. The comparison between the areas of two peaks, one of succinic acid at about $1467 \mathrm{~cm}^{-1}$, made up from a weaker contribution from skeletal carbon in succinic acid $\left(\mathrm{CH}_{2}\right.$ scissoring, $\left.1419 \mathrm{~cm}^{-1}\right)$ and the symmetric stretching of the carboxylate group (around $1467 \mathrm{~cm}^{-1}$, total area $=11.2$ ), and the other at $512 \mathrm{~cm}^{-1}$ that is dependent on the amount of USM nanoparticles $(\delta \mathrm{Fe}-\mathrm{O}$, area $=6.6$ ) yields an area ratio of 1.7 . In comparison, the skeletal carbon signal in [41] is virtually absent from the spectrum. According to our FTIR data we may reasonably assume that the high succinic acid surface coating will translate into a high coating of PEG in the subsequent functionalization step. The FTIR spectrum, through the aforementioned symmetric stretching of the carboxylate group plus the asymmetric stretching at $1574 \mathrm{~cm}^{-1}$ supports that binding to the magnetic core occurs through carboxylate groups, whereas free acid groups are also detected in the spectrum (around $1700 \mathrm{~cm}^{-1}$ ) that must be located on the outside of the particles, as illustrated in Scheme 1.

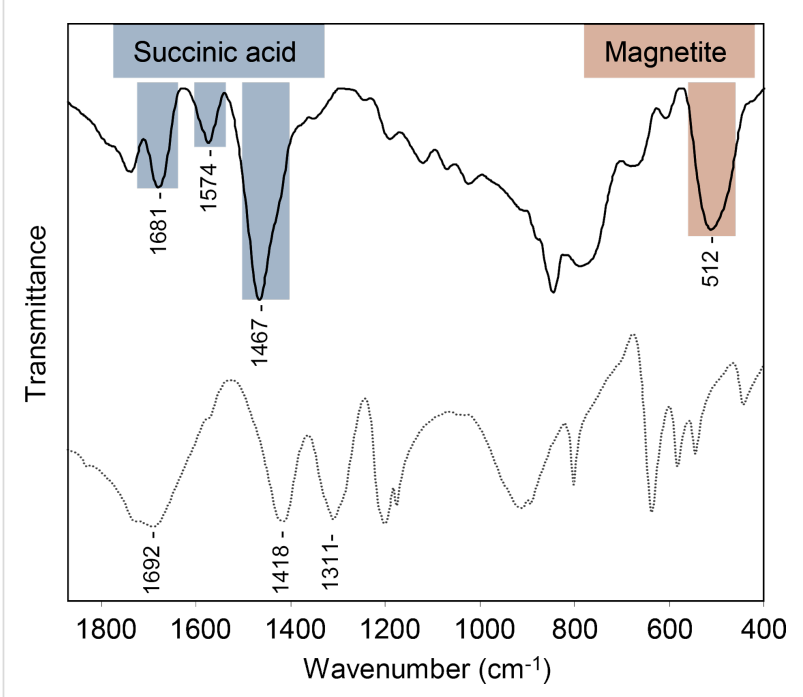

Figure 4: FTIR spectrum of USM-Suc nanoparticles (solid line) and succinic acid (dotted line) as a reference. Highlighted signals are discussed in the text.
In order to covalently attach the amino-terminated polymer PEG onto the nanoparticle surface, a water soluble carbodiimide ( $N$-(3-dimethylaminopropyl)- $N$-ethylcarbodiimide hydrochloride, EDC) was used that conjugates the primary amine group of PEG with the free carboxylic end group of the USM-Suc nanoparticles. EDC was used in tandem with $\mathrm{N}$-hydroxysuccinimide (NHS) to improve the water stability of the carboxylic acid-activated intermediate, and excess PEG was used for maximum coating of nanoparticles [42].

The comparison between the FTIR spectra of USM-Suc and USM-PEG, Figure 4 and Figure 5 respectively, demonstrates that the coupling reaction was successful. The characteristic vibration of the succinic carboxylic acid group in USM-Suc $\left(\mathrm{C}=\mathrm{O}\right.$ stretching mode at $\left.1700 \mathrm{~cm}^{-1}\right)$, disappears in USM-PEG owing to its replacement by an amide bond $\left(1638 \mathrm{~cm}^{-1}\right)$. An even clearer proof of the functionalization is the appearance of intense characteristic bands of PEG at 2891 and $1103 \mathrm{~cm}^{-1}$, corresponding to the ether $\mathrm{C}-\mathrm{H}$ and $\mathrm{C}-\mathrm{O}-\mathrm{C}$ stretching modes, respectively, and the band due to the remaining free primary amine of PEG covalently bonded to the surface of USM (N-H stretching) at $3419 \mathrm{~cm}^{-1}$.

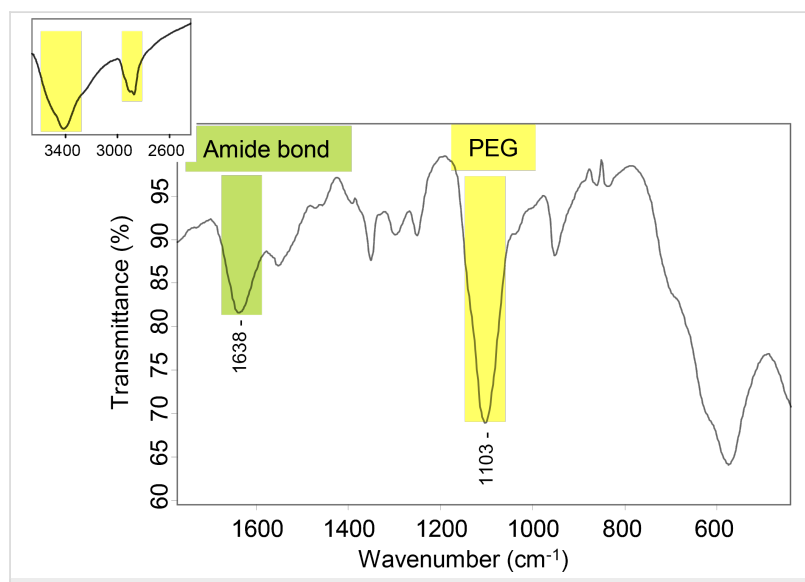

Figure 5: FTIR spectrum of USM-PEG nanoparticles. Highlighted signals are discussed in the text.

It is noteworthy that electrophoretic techniques have also been developed in order to quantitatively determine the number of PEG molecules in gold and quantum dot-PEG conjugates [43].

Loading of CPT on USM and USM-PEG nanoparticles was performed by direct incubation of the drug in an aqueous solution of the nanoparticles to obtain the formulations USM[CPT] and USM-PEG[CPT], respectively, and their maximum loading capacity was calculated by Equation 1:

$$
\mathrm{LC}(\%)=\frac{\text { maximum weight of CPT loaded }}{\text { nanoparticle[CPT] weight }}
$$


The loading capacity was obtained from UV assays according to the details given in Supporting Information File 1, and the results are summarized in Table 2. Both bare and PEGylated nanoparticles were able to take up a substantial amount of CPT. Although the loading capacity of USM bare nanoparticles was not as high as the PEGylated ones, it is still higher than that reported for other polymer-coated USM nanoparticles [33], exceeding even the loading capacity of the prodrug Prothecan $(1.7 \%(\mathrm{w} / \mathrm{w}))[44]$. The extremely high loading capacity of USM-PEG can be attributed to the amphiphilic nature of PEG polymers. It is noteworthy that although PEG is commonly used in block copolymers as hydrophilic moiety, it is soluble in both water and organic solvents owing to the hydrophobic nature of the ethylene groups. Although few examples are known in the literature, PEG polymers have proven their ability to interact with hydrophobic drugs [45].

The chemical integrity of CPT in USM[CPT] and USMPEG[CPT] was investigated by FTIR spectroscopy. As shown in Figure 6 the characteristic peaks of CPT are clearly present in both USM[CPT] and USM-PEG[CPT]. Although taken at a lower resolution, probably due to the lower concentration of CPT loaded in USM[CPT] when compared to USM-PEG[CPT], the USM[CPT] formulation possesses also the characteristic

Table 2: Maximum loading capacities of USM[CPT] and USM-PEG[CPT] nanoparticles calculated according to Equation 1 and compared to [33].

\begin{tabular}{lllr} 
this work & LC $(\%)$ & reference [33] & LC (\%) \\
\hline USM[CPT] & $13.15 \pm 0.05$ & CPT-loaded CS $/ \mathrm{Fe}_{3} \mathrm{O}_{4}$ & $3.47 \pm 0.09$ \\
USM-PEG[CPT] & $26.11 \pm 0.02$ & $\mathrm{CPT}$-loaded OCMCS $/ \mathrm{Fe}_{3} \mathrm{O}_{4}$ & $2.85 \pm 0.05$ \\
& & $\mathrm{CPT}$-loaded $\mathrm{NSOCMCS} / \mathrm{Fe}_{3} \mathrm{O}_{4}$ & $3.01 \pm 0.06$
\end{tabular}

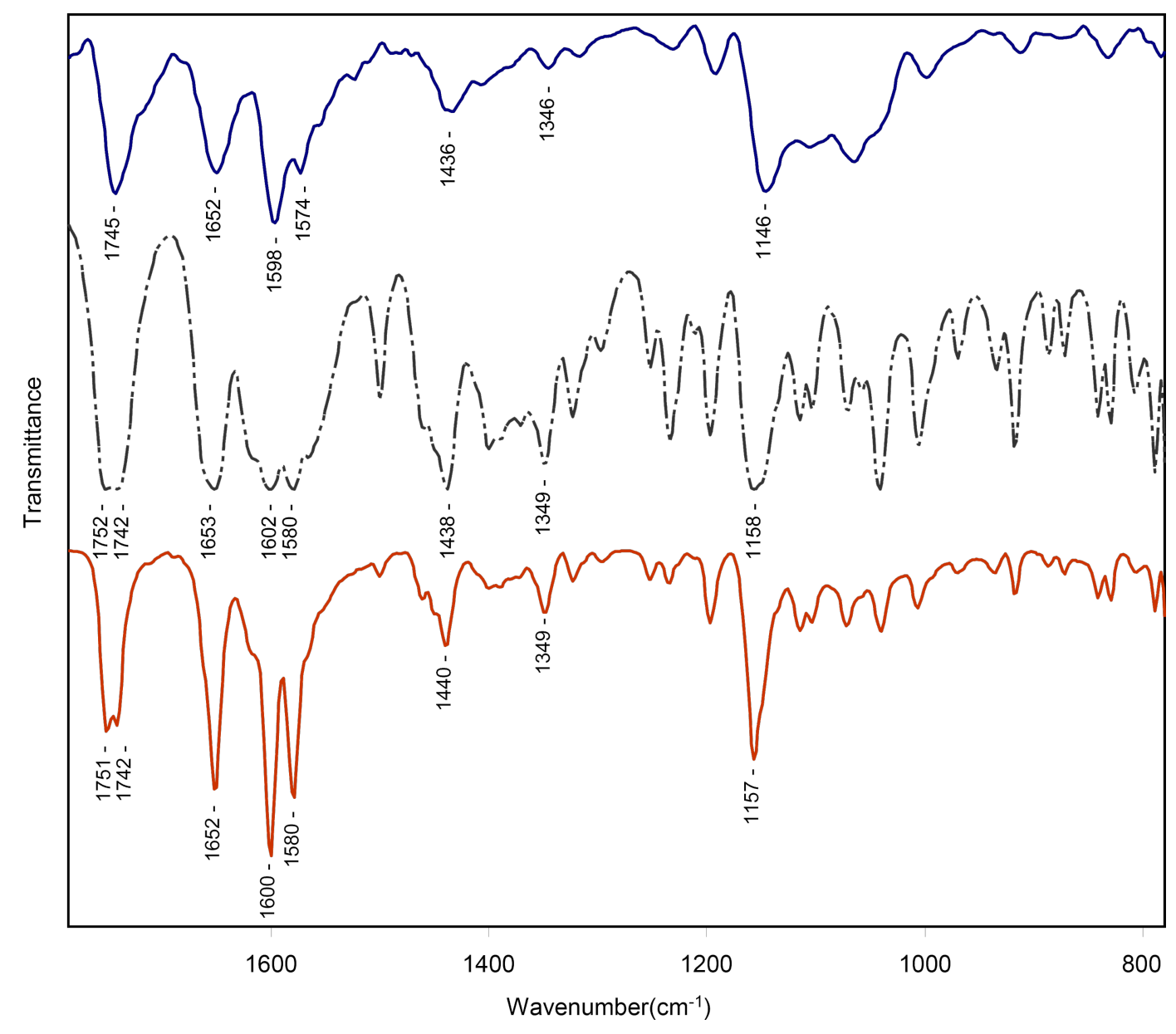

Figure 6: Infrared spectra of USM[CPT] (top, blue solid line), CPT (center, grey dotted line) and USM-PEG[CPT] (bottom, red solid line). 
peaks of its CPT load. Differences in intensity and a shift are expected and obtained between the characteristic bands of CPT in USM[CPT] and USM-PEG[CPT], owing to the different nature of the nanoparticle surface, which results in different interactions with CPT. It is noteworthy that the characteristic lactone band at $1750 \mathrm{~cm}^{-1}(\mathrm{C}=\mathrm{O}$ stretching vibration of lactone $)$ is retained in both USM[CPT] and USM-PEG[CPT] spectra, indicating that the chemical integrity of CPT in nanoconjugates is not affected during the formulation process.

As chemical integrity of CPT is related to its biological activity, the formulations were tested in a biological setting for their efficiency in inducing apoptosis. Apoptosis was assessed by the occurrence of cells with nuclear condensation and fragmenta- tion by Hoechst staining [46]. In order to compare the apoptotic activity of USM[CPT] and USM-PEG[CPT] formulations, stock solutions were prepared, and suitable amounts were taken so that the provided final concentration of CPT was identical to that used in the pure CPT control. According to our results, neither USM nor USM-PEG nanoparticles induce apoptosis in lung cancer cell line cultures H460, while USM[CPT] and USM-PEG[CPT], as well as CPT itself, induced apoptosis (Figure 7). The apoptotic levels obtained with both USM[CPT] and USM-PEG[CPT] formulations are comparable to that obtained with CPT. The slight activity decrease observed in formulations when compared to CPT (about 10-15\%) is probably due to the release profile of the drug from the formulations, since an increase of the time during which the cell cultures are

A)
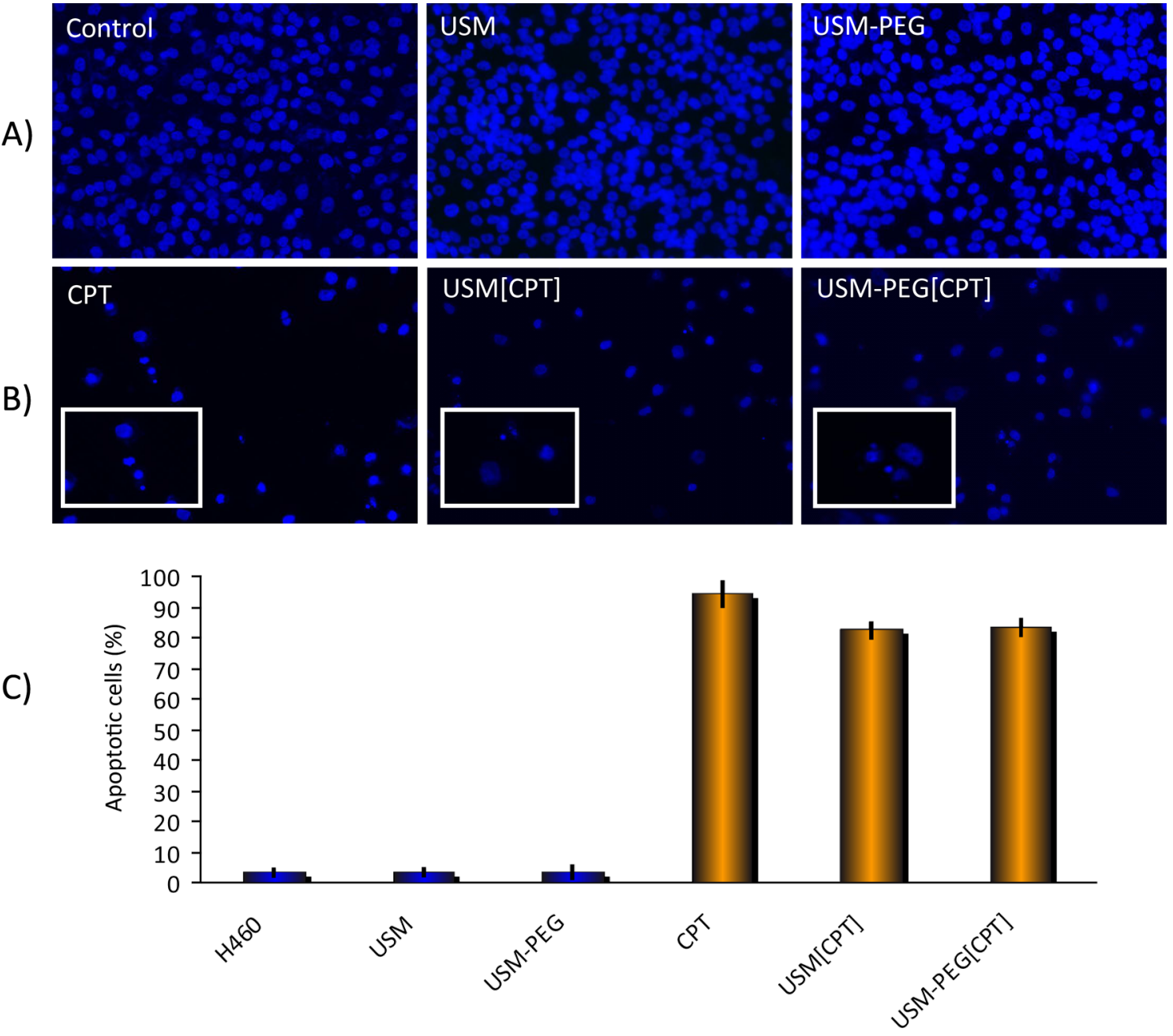

Figure 7: A: Fluorescence microscopy images of H460 cell cultures: control (left); with bare USM (middle); with PEGylated USM (right). B: Fluorescence microscopy images of the H460 cell culture loaded with: CPT (left); USM[CPT] formulation (middle); USM-PEG[CPT] formulation (right) and details of apoptotic nuclei (inserted). C: Percentage of apoptotic cell nuclei in H460 cell cultures: From left to right, control, with bare USM, with PEGylated USM, with CPT, with USM[CPT], USM-PEG[CPT]. Stock dispersions of USM[CPT] and USM-PEG[CPT] were prepared in PBS (pH 7.5) with a CPT concentration of $5 \mathrm{mM}$, and $1 \mu \mathrm{L}$ of this dispersion was added to $\mathrm{H} 460$ cells previously cultured (confluent; $1 \mathrm{~mL}$ final volume, $5 \mu \mathrm{M}$ final $\mathrm{CPT}$ concentration). Cells with nanoparticles and references were incubated at $37^{\circ} \mathrm{C}$ for $48 \mathrm{~h}$. More than 100 cells were examined for each experimental condition. $P<0.05$ significant differences with respect to control cells. 
incubated with the formulations leads to an increased apoptosis (data not shown).

In summary, two new CPT formulations based on iron oxide superparamagnetic nanoparticles have been described and characterized by FTIR. Both formulations retain the biological activity of CPT and exhibit remarkable cytotoxic activity towards H460 lung cancer cell line cultures. Remarkably, it was found that iron oxide superparamagnetic nanoparticles synthesized by co-precipitation method can be loaded with CPT. By the proposed nanoparticle surface modification procedure with PEG the amount of CPT that can be loaded was greatly enhanced (in effect doubled) with respect to bare USM nanoparticles. No significant difference in the cytotoxic activity was observed among the CPT loaded on either the PEGylated or bare USM magnetic nanoparticles. Nevertheless, a different in vivo behaviour of PEGylated and non-PEGylated USM nanoparticles cannot be ruled out, as longer circulation times are expected for the PEGylated ones. Additionally, we envisage that the developed USM-PEG may form targeted-delivery systems by exploiting the free amine groups on their surface for covalent attachment of targeting cargoes such as antibodies.

\section{Supporting Information}

\section{Supporting Information File 1}

General procedures.

[http://www.beilstein-journals.org/bjnano/content/ supplementary/2190-4286-5-144-S1.pdf]

\section{Acknowledgements}

This work was supported by Fundación Progreso y Salud, Consejería de Salud (PI0070) and Proyecto de Investigación de Excelencia de la Junta de Andalucía (P10-FQM-6615). Dr. Alberto Casu is kindly acknowledged for magnetic measurements.

\section{References}

1. Wall, M. E.; Wani, M. C. J. Ethnopharmacol. 1996, 51, 239-254. doi:10.1016/0378-8741(95)01367-9

2. Takimoto, C. H.; Wright, J.; Arbuck, S. G. Biochim. Biophys. Acta 1998, 1400, 107-119. doi:10.1016/S0167-4781(98)00130-4

3. Pantazis, P.; Giovanella, B. C.; Rothenberg, M. L. ACS Symp. Ser. 1996, 803, 1-335.

4. Rothenberg, M. L. Ann. Oncol. 1997, 8, 837-855. doi:10.1023/A:1008270717294

5. Castelli, S.; Coletta, A.; D'Annessa, I.; Fiorani, P.; Tesauro, C.; Desideri, A. Biol. Chem. 2012, 393, 1327-1340. doi:10.1515/hsz-2012-0240

6. Li, Q.-Y.; Zu, Y.-G.; Shi, R.-Z.; Yao, L.-P. Curr. Med. Chem. 2006, 13, 2021-2039. doi:10.2174/092986706777585004

7. Li, L.; Feng, Y.; Ren, T.; Li, Y. Huaxue Tongbao 2011, 74, 803-809.
8. Brannon-Peppas, L.; Blanchette, J. O. Adv. Drug Delivery Rev. 2004, 56, 1649-1659. doi:10.1016/j.addr.2004.02.014

9. Jabr-Milane, L. S.; van Vlerken, L. E.; Yadav, S.; Amiji, M. M. Cancer Treat. Rev. 2008, 34, 592-602. doi:10.1016/j.ctrv.2008.04.003

10. Sultana, S.; Khan, M. R.; Kumar, M.; Kumar, S.; Ali, M. J. Drug Targeting 2013, 21, 107-125. doi:10.3109/1061186X.2012.712130

11. Cortesi, R.; Esposito, E.; Maietti, A.; Menegatti, E.; Nastruzzi, C. Int. J. Pharm. 1997, 159, 95-103. doi:10.1016/S0378-5173(97)00275-5

12. Lundberg, B. B. Anti-Cancer Drug Des. 1998, 13, 453-461.

13. Kang, J.; Kumar, V.; Yang, D.; Chowdhury, P. R.; Hohl, R. J. Eur. J. Pharm. Sci. 2002, 15, 163-170. doi:10.1016/S0928-0987(01)00214-7

14. Saetern, A. M.; Nguyen, N. B.; Bauer-Brandl, A.; Brandl, M. Int. J. Pharm. 2004, 284, 61-68. doi:10.1016/j.ijpharm.2004.07.014

15. Martins, S.; Tho, I.; Reimold, I.; Fricker, G.; Souto, E.; Ferreira, D.; Brandl, M. Int. J. Pharm. 2012, 439, 49-62. doi:10.1016/j.ijpharm.2012.09.054

16. Zu, Y.; Wang, D.; Zhao, X.; Jiang, R.; Zhang, Q.; Zhao, D.; Li, Y.; Zu, B.; Sun, Z. Int. J. Mol. Sci. 2011, 12, 4237-4249. doi:10.3390/ijms12074237

17. Ge, J.; Neofytou, E.; Lei, J.; Beygui, R. E.; Zare, R. N. Small 2012, 8, 3573-3578. doi:10.1002/smll.201200889

18. Çırpanlı, Y.; Allard, E.; Passirani, C.; Bilensoy, E.; Lemaire, L.; Çalış, S.; Benoit, J. P. Int. J. Pharm. 2011, 403, 201-206. doi:10.1016/j.ijpharm.2010.10.015

19. Kieler-Ferguson, H. M.; Fréchet, J. M. J.; Szoka, F. C., Jr. Wiley Interdiscip. Rev.: Nanomed. Nanobiotechnol. 2013, 5, 130-138. doi:10.1002/wnan.1209

20. Weiss, G. J.; Chao, J.; Neidhart, J. D.; Ramanathan, R. K.; Bassett, D.; Neidhart, J. A.; Choi, C. J.; Chow, W.; Chung, V.; Forman, S. J.; Garmey, E.; Hwang, J.; Kalinoski, D. L.; Koczywas, M.; Longmate, J.; Melton, R. J.; Morgan, R.; Oliver, J.; Peterkin, J. J.; Ryan, J. L.; Schluep, T.; Synold, T. W.; Twardowski, P.; Davis, M. E.; Yen, Y. Invest. New Drugs 2013, 31, 986-1000. doi:10.1007/s10637-012-9921-8

21. Bhojani, M. S.; Van Dort, M.; Rehemtulla, A.; Ross, B. D. Mol. Pharmacol. 2010, 7, 1921-1929. doi:10.1021/mp100298r

22. Chertok, B.; Moffat, B. A.; David, A. E.; Yu, F.; Bergemann, C.; Ross, B. D.; Yang, V. C. Biomaterials 2008, 29, 487-496. doi:10.1016/j.biomaterials.2007.08.050

23. Colombo, M.; Carregal-Romero, S.; Casula, M. F.; Gutiérrez, L.; Morales, M. P.; Böhm, I. B.; Heverhagen, J. T.; Prosperi, D.; Parak, W. J. Chem. Soc. Rev. 2012, 41, 4306-4334. doi:10.1039/c2cs15337h

24. Pankhurst, Q. A.; Connolly, J.; Jones, S. K.; Dobson, J. J. Phys. D: Appl. Phys. 2003, 36, R167-R181. doi:10.1088/0022-3727/36/13/201

25. Lutz, J.-F.; Stiller, S.; Hoth, A.; Kaufner, L.; Pison, U.; Cartier, R. Biomacromolecules 2006, 7, 3132-3138. doi:10.1021/bm0607527

26. Xie, J.; Lee, S.; Chen, X. Adv. Drug Delivery Rev. 2010, 62, 1064-1079. doi:10.1016/j.addr.2010.07.009

27. Sadighian, S.; Rostamizadeh, K.; Hosseini-Monfared, H.; Hamidi, M. Colloids Surf., B 2014, 117, 406-413. doi:10.1016/j.colsurfb.2014.03.001

28. Filippousi, M.; Papadimitriou, S. A.; Bikiaris, D. N.; Pavlidou, E.; Angelakeris, M.; Zamboulis, D.; Tian, H.; Van Tendeloo, G. Int. J. Pharm. 2013, 448, 221-230. doi:10.1016/j.ijpharm.2013.03.025

29. Mornet, S.; Vasseur, S.; Grasset, F.; Duguet, E. J. Mater. Chem. 2004, 14, 2161-2175. doi:10.1039/b402025a 
30. Melancon, M. P.; Lu, W.; Li, C. Mater. Res. Bull. 2009, 34, 415-421. doi:10.1557/mrs2009.117

31. Saba, A. R.; Castillo, P. M.; Fantechi, E.; Sangregorio, C.; Lascialfari, A.; Sbarbati, A.; Casu, A.; Falqui, A.; Casula, M. F. Proc. SPIE 2013, 8595, 85950Z. doi:10.1117/12.2003180

32. Cengelli, F.; Grzyb, J. A.; Montoro, A.; Hofmann, H.; Hanessian, S.; Juillerat-Jeanneret, L. ChemMedChem 2009, 4, 988-997. doi:10.1002/cmdc.200800424

33. Zhu, A.; Luo, X.; Dai, S. J. Mater. Res. 2009, 24, 2307-2315. doi:10.1557/jmr.2009.0284

34. Mahmoudi, M.; Sant, S.; Wang, B.; Laurent, S.; Sen, T. Adv. Drug Delivery Rev. 2011, 63, 24-46. doi:10.1016/j.addr.2010.05.006

35. Owens, D. E., III; Peppas, N. A. Int. J. Pharm. 2006, 307, 93-102. doi:10.1016/j.ijpharm.2005.10.010

36. Yu, M.; Huang, S.; Yu, K. J.; Clyne, A. M. Int. J. Mol. Sci. 2012, 13, 5554-5570. doi:10.3390/ijms13055554

37. Rowinsky, E. K.; Rizzo, J.; Ochoa, L.; Takimoto, C. H.; Forouzesh, B.; Schwartz, G.; Hammond, L. A.; Patnaik, A.; Kwiatek, J.; Goetz, A.; Denis, L.; McGuire, J.; Tolcher, A. W. J. Clin. Oncol. 2003, 21, 148-157. doi:10.1200/JCO.2003.03.143

38. Bee, A.; Massart, R.; Neveu, S. J. Magn. Magn. Mater. 1995, 149, 6-9. doi:10.1016/0304-8853(95)00317-7

39. Casula, M. F.; Corrias, A.; Arosio, P.; Lascialfari, A.; Sen, T.; Floris, P.; Bruce, I. J. J. Colloid Interface Sci. 2011, 357, 50-55. doi:10.1016/j.jcis.2011.01.088

40. Corrias, A.; Mountjoy, G.; Loche, D.; Puntes, V.; Falqui, A.; Zanella, M.; Parak, W. J.; Casula, M. F. J. Phys. Chem. C 2009, 113, 18667-18675. doi:10.1021/jp9047677

41. Singh, S.; Barick, K. C.; Bahadur, D. J. Hazard. Mater. 2011, 192, 1539-1547. doi:10.1016/j.jhazmat.2011.06.074

42. Fernandez-Montesinos, R.; Castillo, P. M.; Klippstein, R.; Gonzalez-Rey, E.; Mejías, J. A.; Zaderenko, A. P.; Pozo, D. Nanomedicine 2009, 4, 919-930. doi:10.2217/nnm.09.79

43. Sperling, R. A.; Pellegrino, T.; Li, J. K.; Chang, W. H.; Parak, W. J. Adv. Funct. Mater. 2006, 16, 943-948. doi:10.1002/adfm.200500589

44. Scott, L. C.; Yao, J. C.; Benson, A. B., III; Thomas, A. L.; Falk, S.; Mena, R. R.; Picus, J.; Wright, J.; Mulcahy, M. F.; Ajani, J. A.; Evans, T. R. J. Cancer Chemother. Pharmacol. 2009, 63, 363-370. doi:10.1007/s00280-008-0746-2

45. Li, Y.-C.; Rissanen, S.; Stepniewski, M.; Cramariuc, O.; Róg, T.; Mirza, S.; Xhaard, H.; Wytrwal, M.; Kepczynski, M.; Bunker, A. J. Phys. Chem. B 2012, 116, 7334-7341. doi:10.1021/jp300301z

46. Oropesa-Ávila, M.; Fernández-Vega, A.; de la Mata, M.; Maraver, J. G.; Cordero, M. D.; Cotán, D.; de Miguel, M.; Calero, C. P.; Paz, M. V.; Pavón, A. D.; Sánchez, M. A.; Zaderenko, A. P.; Ybot-González, P.; Sánchez-Alcázar, J. A. Cell Death Dis. 2013, 4, e527. doi:10.1038/cddis.2013.58

\section{License and Terms}

This is an Open Access article under the terms of the Creative Commons Attribution License

(http://creativecommons.org/licenses/by/2.0), which permits unrestricted use, distribution, and reproduction in any medium, provided the original work is properly cited.

The license is subject to the Beilstein Journal of Nanotechnology terms and conditions: (http://www.beilstein-journals.org/bjnano)

The definitive version of this article is the electronic one which can be found at:

doi:10.3762/bjnano.5.144 